Ciência Florestal, Santa Maria, v. 27, n. 4, p. 1415-1428, out.-dez., 2017

ISSN 1980-5098

\title{
ESTRUTURA DA COMUNIDADE ARBÓREA E CARACTERÍSTICAS EDÁFICAS DE UM FRAGMENTO URBANO
}

\author{
STRUCTURE OF THE TREE COMMUNITY AND EDAPHIC CHARACTERISTICS OF AN \\ URBAN FRAGMENT
}

\author{
Vagner Santiago Vale ${ }^{1}$ Glein Monteiro Araújo ${ }^{2}$ Alexandre Silva de Oliveira ${ }^{3}$ \\ Jamir Afonso Prado-Júnior ${ }^{4}$ Lilian Cristina da Silva Santos ${ }^{5}$
}

\begin{abstract}
RESUMO
No Brasil há diversos municípios com fragmentos florestais inseridos no perímetro urbano sob ameaça de degradação. AMata do Desamparo (Araguari -MG)é uma importante formaçãoflorestal que protege nascentes existentes em um parque urbano. O objetivo desse estudo foi realizar o levantamento fitossociológico da vegetação arbórea do gradiente florestal e realizar análises de solo. Foram plotadas 25 parcelas de 20 x $20 \mathrm{~m}$, dispostas em quatro blocos e amostrados todos os indivíduos arbóreos com circunferência a $1,30 \mathrm{~m} \geq 15 \mathrm{~cm}$ e também coletadas amostras de solo a $0-20 \mathrm{~cm}$ de profundidade para análises químicas, umidade do solo e o desnível do terreno. Para averiguar se as propriedades químicas, umidade do solo e o desnível influenciaram na distribuição das espécies vegetais do fragmento florestal foi realizada a análise de correspondência canônica (CCA). A comunidade apresentou elevada riqueza (94 espécies) e número de indivíduos (1760) muito elevado em relação a outras florestas da região e adensamentos de espécies de borda e comuns de áreas abertas mesmo na região mais interiorana da floresta, o que indica que existem impactos antrópicos sobre a comunidade arbórea. A CCA demonstrou a heterogeneidade ambiental com a formação de três grupos, um formado pelas parcelas próximas ao leito do rio com maior umidade do solo e menor desnível, outro formado por parcelas com grande desnível, com predominância de espécies generalistas consideradas típicas de florestas estacionais semideciduais e outro fortemente correlacionado com alumínio. Assim, este fragmento florestal pode ser considerado um importante relicto urbano com grande riqueza de espécies, no entanto, impactos passados influenciaram a estrutura da comunidade arbórea, que está em um estágio intermediário de sucessão.
\end{abstract}

Palavras-chave: análise de correspondência canônica; fitossociologia; Mata do Desamparo.

\begin{abstract}
In Brazil, there are forest fragments inserted in the urban area under threat of degradation. The Desamparo Forest (Araguari-MG) is an important forest protecting springs at an urban park. This study aimed the phytosociological survey of trees from a forest gradient and perform soil analysis. Twenty-five plots of 20 x $20 \mathrm{~m}$ were plotted and sampled all trees with the $1.30 \mathrm{~m} \geq 15 \mathrm{~cm}$ of circumference and also collected soil samples at 0-20 cm depth for chemical analysis as well as soil moisture and the slope of the terrain. To

1 Biólogo, Dr., Professor Estatutário da Universidade Estadual de Goiás, Câmpus Ipameri, Rodovia GO 330, Km 241, Anel Viário, CEP 75780-000, Ipameri (GO), Brasil. vagner.vale@ueg.br

2 Biólogo, Dr., Professor Aposentado da Universidade Federal de Uberlândia, Câmpus Umuarama, Av. Pará, 1720, CEP 38405-320, Uberlândia (MG), Brasil. glein@ufu.br

3 Biólogo, MSc., Analista Ambiental do Instituto Chico Mendes de Conservação da Biodiversidade, Av. Brigadeiro Haroldo Velloso, CEP 68181-030, Itaituba (PA), Brasil. bonderbi@hotmail.com

4 Biólogo, Dr., Bolsista de Pós-Doutorado pelo Conselho Nacional de Desenvolvimento Científico e Tecnológico, Universidade Federal de Uberlândia, Câmpus Umuarama, Av. Pará, 1720, CEP 38405-320, Uberlândia (MG), Brasil. jamirjúnior@yahoo.com.br

5 Bióloga, Mestranda do Curso de Pós-Graduação stricto sensu em Produção Vegetal, Universidade Estadual de Goiás, Câmpus Ipameri, Rod. GO 330, Km 241, Anel Viário, CEP 75780-000, Ipameri (GO), Brasil. liliancristina_2011@hotmail.com
\end{abstract}

Recebido para publicação em 15/04/2015 e aceito em 20/07/2016

Ci. Fl., v. 27, n. 4, out.-dez., 2017 
determine whether the chemical properties, soil moisture and the slope influenced the distribution of plant species in the forest fragment, it was performed canonical correspondence analysis (CCA). The community had a very high number of species (94) and trees (1760), with occurrence of edge species and common open areas even in the forest hinterland, which indicates that there are human impacts on the community. CCA showed the environmental heterogeneity with the formation of three groups, one formed by the plots near to the river bed with higher soil moisture and lower slope, other plots formed with large slope with predominance of generalist species of dry forest, and other strongly correlated aluminum. Therefore, this forest fragment can be considered an important urban relict with high species richness, however past impacts influence the structure of the tree community, which is in an intermediate stage of succession.

Keywords: canonical correspondence analysis; 'Desamparo' forest; phytossociology.

\section{INTRODUÇÃO}

A região do Triângulo Mineiro tem histórico de conversão de florestas em pastagens e grandes culturas, além da crescente urbanização (LOPES et al., 2012). Na região existem poucos fragmentos remanescentes desta antropização e raramente são considerados em bom estádio de conservação, mesmo quando localizados em zonas rurais (LOPES et al., 2012). Alguns destes fragmentos são encontrados em bosques e parques urbanos e ainda conservam alta riqueza de espécies vegetais nativas (ARAÚJO; GUIMARÃES; NAKAJIMA, 1997; ROSA; SCHIAVINI, 2006), apesar de serem utilizados como áreas de lazer e abertos à visitação pública (SANTIN, 1999), são escassos os estudos que avaliem sua composição florística e estrutura. Inúmeros fatores de perturbação, como trilhas excessivas, lixo, invasões biológicas, entre outros, degradam esses fragmentos e deterioram seu potencial ecológico e a autossustentabilidade das populações de muitas espécies (BADIRU; PIRES; RODRIGUEZ, 2005). Por outro lado, o aproveitamento desses fragmentos como áreas de lazer pode minimizar a ação de alguns fatores de perturbação, como incêndios, extração de madeira e invasão por gado (SANTIN, 1999) que, em geral, ocorrem nos fragmentos florestais fora da área urbana.

No Brasil, a destinação desses espaços com o intuito de preservação e melhoria da qualidade ambiental urbana vem crescendo nos últimos anos (SIQUEIRA, 2008). Em geral, por serem pequenos e submetidos a diversas interferências antrópicas, esses fragmentos apresentam muitas clareiras e ocorrência de espécies invasoras e exóticas (CIELO FILHO; SANTIN, 2002), tornando o conhecimento da evolução sucessional da vegetação imprescindível para o manejo e ordenamento correto de sua conservação (RAMOS; BOLDO, 2007).

Alguns fragmentos urbanos apresentam gradientes edáficos e topográficos abrigando florestas de galeria, floresta semidecidual e cerradão (GUILHERME et al., 1998; SALLES; SCHIAVINI, 2007), com estrutura e composição florística distintas. Desse modo, é fundamental verificar a importância dos gradientes edáficos e sua influência na composição de espécies e estrutura da vegetação desses fragmentos florestais. Quanto maior a heterogeneidade edáfica, maior será a variação espacial das espécies vegetais e maior será o valor do fragmento para a conservação. Diversos trabalhos de florística e fitossociologia (ARAÚJO; GUIMARÃES; NAKAJIMA, 1997; GUILHERME; NAKAGIMA, 2007; LOPES et al., 2012) foram realizados em fragmentos florestais urbanos, porém, nenhum deles contemplou os aspectos ambientais, como características edáficas e topográficas, e as suas relações com o gradiente de vegetação existente no local.

Em Araguari, há um bosque urbano criado em 1989 (Lei Municipal no 2529) chamado de Mata do Desamparo, um fragmento de vegetação nativa que protege algumas nascentes do córrego do Desamparo. Apesar dessa função ecológica extremamente importante, parte da vegetação foi retirada durante a expansão urbana, e houve plantio de espécies exóticas próximo da floresta. Atualmente, a Mata do Desamparo é constituída por um gradiente de cerradão, floresta estacional semidecidual, e floresta de galeria (censo IBGE, 2012). O local é utilizado como área de lazer, contudo, é carente de fiscalização, permitindo o fluxo de pessoas no local, possibilitando a introdução de espécies exóticas. Por estas razões, o objetivo desse estudo foi realizar o levantamento fitossociológico da comunidade arbórea do gradiente do fragmento florestal situado no Parque Municipal da Mata do Desamparo, com intuito de compreender as variações na estrutura do compartimento arbóreo da floresta. 


\section{MATERIAL E METÓDOS}

\section{Área de estudo}

O Parque Municipal da Mata do Desamparo (Figura 1) situa-se no perímetro urbano da cidade de Araguari - MG (48 $12^{\circ} 05^{\prime} \mathrm{O}$ e $18^{\circ} 40^{\prime} 30^{\prime}$ 'S) e possui área aproximada de 28 hectares. O fragmento de vegetação nativa constituiu-se em maior parte de uma floresta estacional semidecidual tendo em sua parte inferior uma floresta de galeria, margeando as nascentes do córrego Desamparo, e na parte superior uma faixa de cerradão. A área florestal mais preservada ocupa aproximadamente 11 hectares do Parque e o restante são áreas abertas ou em fase de regeneração.

O clima de Araguari é classificado como tropical de savana (Aw Megatérmico de Köppen), caracterizado por verões chuvosos (outubro a abril) e invernos secos (maio a setembro) e pluviosidade anual média de 1499 mm (SANTOS; ASSUNÇÃO, 2006). A maior parte da área ocorre sobre Latossolo Vermelho Amarelo com textura arenosa, mas nos locais próximos ao córrego do Desamparo o solo é hidromórfico, apresentando coloração acinzentada e textura argilosa.

\section{Levantamento fitossociológico}

O levantamento fitossociológico da vegetação arbórea foi realizado em 25 parcelas de $20 \times 20 \mathrm{~m}$, totalizando um hectare de área amostrada, seguindo o protocolo do "Manual para o Monitoramento de Parcelas Permanentes nos Biomas Cerrado e Pantanal" (FELFILI; CARVALHO, F. A.; HAIDAR, 2005). As parcelas foram arranjadas em quatro blocos, três de seis parcelas e um de sete parcelas (Figura 1). O bloco 1 (mais próximo ao curso do Córrego do Desamparo), no qual foram plotadas as parcelas 1 a 6; o bloco 2 (parcelas 7 a 13) e 3 (parcelas 14 a19) estão no interior da floresta (existe uma trilha recente entre

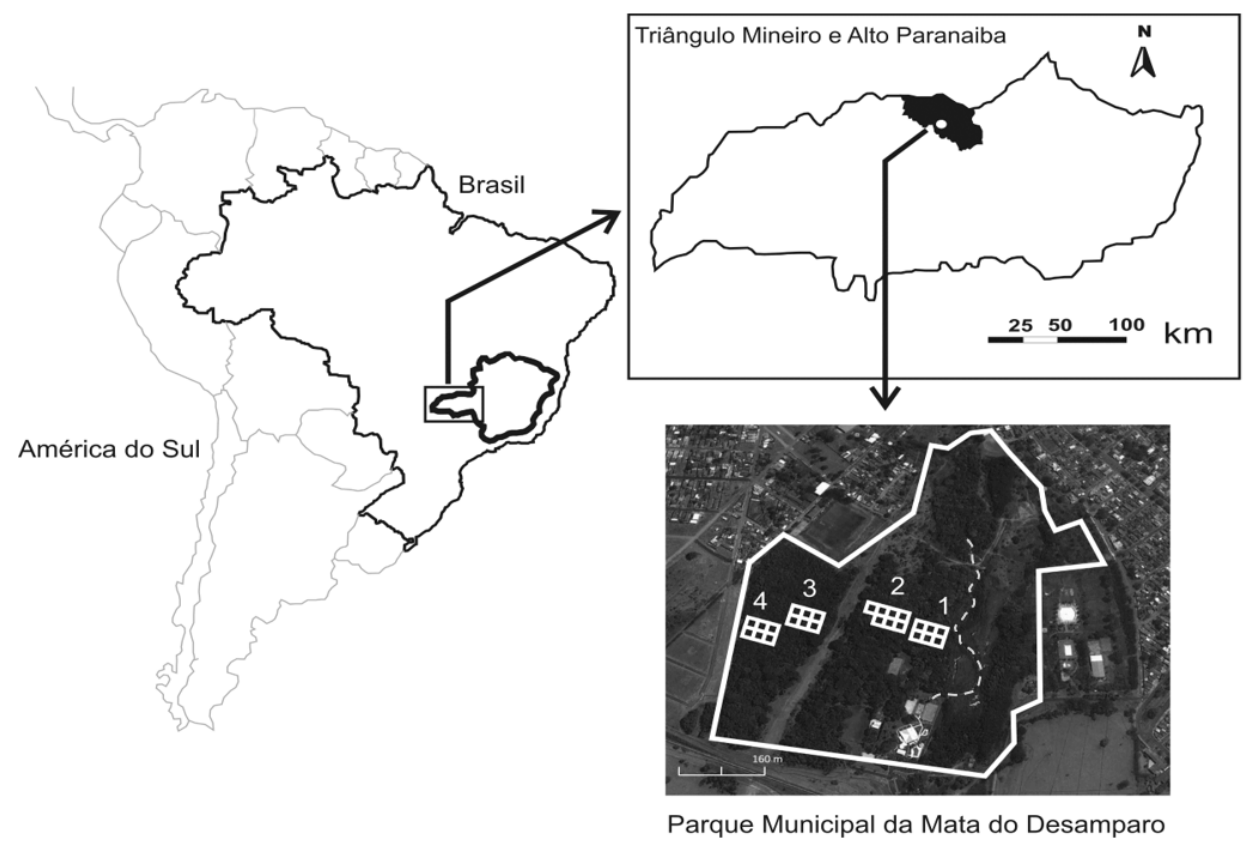

FIGURA 1: Localização das parcelas permanentes plotadas no gradiente florestal do Parque Municipal da Mata do Desamparo, Araguari -MG. Linha contígua delimita a área do Parque, os quadrados são as parcelas amostrais e a linha tracejada demonstra o Córrego do Desamparo.

FIGURE 1: Location of the permanent plots in the Mata do Desamparo Municipal City Park forest gradient, Araguari-MG. The contiguous line delimits the Park area, the squares are the plots location and the dashed line represents the Desamparo Stream. 
estes dois blocos) enquanto que o bloco 4 (parcelas 20 a 25) se localiza distante do córrego e está próximo à borda da floresta, em que está caracterizado um cerradão (Figura 1). As parcelas foram marcadas nas áreas mais preservadas da floresta, seguindo a partir do córrego (parte mais baixa do relevo) em direção à parte mais alta do relevo.

Todas as árvores vivas e mortas com circunferência a altura do peito (CAP) $\geq 15 \mathrm{~cm}$ foram incluídas no levantamento. Para cada espécie amostrada foram calculados os valores relativos de densidade, frequência, dominância e valor de importância (VI), além do índice de diversidade de Shannon-Wiener (H') para a comunidade arbórea. Esses parâmetros foram calculados utilizando-se o programa Fitopac (SHEPHERD, 2004). A maior parte dos indivíduos foi identificada no local e aqueles não identificados foram coletados e identificados por especialistas ou por comparações com material depositado no Herbário da Universidade Federal de Uberlândia (HUFU) e no Laboratório de Ecologia Vegetal da Universidade Federal de Uberlândia. Os dados florísticos contendo famílias, gêneros e espécies encontrados nas áreas, foram organizados de acordo com o Angiosperm Phylogeny Group III (ANGIOSPERM PHYLOGENY GROUP, 2009). Após análises prévias, considerando-se as variáveis ambientais e as fitofisionomias predominantes nos blocos amostrais, foi realizada uma média ponderada do número de indivíduos por parcela para espécies com mínimo de 10 indivíduos. Em seguida foi realizada uma proporção baseado nos valores obtidos. Desta forma foi possível estabelecer em quais blocos as espécies foram proporcionalmente mais densas. As espécies com valores superiores a 50\% no bloco 1 foram consideradas típicas da floresta de galeria, as com mais de $50 \%$ nos blocos 2 e 3 , foram consideradas típicas do trecho central de floresta estacional semidecidual, aquelas com mais de $50 \%$ no bloco 4 , foram consideradas espécies de cerradão e aquelas que não atingiram densidade de $50 \%$ em nenhum trecho amostral, foram consideradas generalistas na área. Este método foi utilizado pelo fato do número de parcelas nos blocos serem distintos.

\section{Solo e declividade}

Para cada parcela foi coletado o solo a uma profundidade de 0 a $20 \mathrm{~cm}$ em três pontos diferentes, formando uma amostra composta por parcela. Foram determinados o $\mathrm{pH}$, o índice de saturação por bases $(\mathrm{V} \%)$, o índice de saturação por alumínio trocável $(\mathrm{m} \%)$ e as concentrações de fósforo $(\mathrm{P})$, potássio $\left(\mathrm{K}^{1+}\right)$, cálcio $\left(\mathrm{Ca}^{2+}\right)$, magnésio $\left(\mathrm{Mg}^{2+}\right)$ e alumínio $\left(\mathrm{Al}^{3+}\right)$. As análises químicas foram realizadas no Laboratório de Análises de Solos do Instituto de Ciências Agrárias da Universidade Federal de Uberlândia. Foi calculado o percentual de umidade do solo (umidade para a base de massa) de cada parcela. As amostras de solo para análise da umidade foram coletadas no mês de março (final da estação chuvosa) em diferentes profundidades $(0-10,50-60,100-110 \mathrm{~cm}$ e $150-160 \mathrm{~cm})$ utilizando-se um trado de caçamba com diâmetro de $5 \mathrm{~cm}$. O solo coletado foi colocado em cápsulas de alumínio, imediatamente tampadas e lacradas com fita adesiva para evitar a perda de umidade. As amostras foram pesadas utilizando-se uma balança de precisão (massa fresca do solo) e posteriormente colocadas em estufa a $110^{\circ} \mathrm{C}$ por 24 horas. Posteriormente, foram novamente pesadas (massa seca do solo) e obtida a umidade para a base de massa (UBM) através da fórmula $\mathrm{UBM}=100(\mathrm{a}-\mathrm{b}) / \mathrm{b}$, em que: $\mathrm{a}=$ peso da massa do solo úmido e $\mathrm{b}=$ peso da massa do solo seco (EMBRAPA, 1997). Os dados de declividade (em graus) das parcelas foram medidos com clinômetro (Geomaster TAL 150) e trena (OLIVEIRA-FILHO et al., 1994).

\section{Análises estatísticas}

Para testar diferenças entre as variáveis de solo entre os blocos foi realizada uma análise de variância (ANOVA), seguindo-se do teste a posteriori de Tukey. Para testar a influência das características do solo (variáveis químicas e umidade) e da declividade na distribuição das espécies vegetais do fragmento florestal, foi realizada uma análise de correspondência canônica (CCA). Esta análise é a mais indicada para a obtenção de uma relação mais estreita entre variáveis ambientais e abundância de espécies (KENT; COKER, 1992). Foram preparadas duas matrizes: uma com a abundância de cada espécie em cada parcela amostral e outra com as características do solo (variáveis químicas e umidade para a base de massa), e a declividade de cada parcela. Foram incluídas nesta análise apenas as espécies com pelo menos 10 indivíduos amostrados. A eliminação das espécies menos abundantes reduz a produção de ruídos na análise de ordenação 
(CAUSTON, 1988). Além disso, variáveis do solo altamente correlacionadas (correlação superior a 0,9) foram retiradas da análise. Após a realização da CCA preliminar, foram eliminadas oito variáveis $(\mathrm{pH}, \mathrm{Ca}$, $\mathrm{Mg}, \mathrm{V} \%, \mathrm{~m} \%$, umidade do solo de 0 a $10 \mathrm{~cm}$, de 50 a $60 \mathrm{~cm}$ e de 100 a $110 \mathrm{~cm}$ de profundidade) fracamente correlacionadas ou altamente redundantes com outras variáveis. Assim, as variáveis utilizadas para a CCA foram saturação por alumínio, fósforo $(\mathrm{P})$, umidade do solo, matéria orgânica, potássio (K) e desnível. Foi utilizado o teste de permutação (999 permutações) e de Monte Carlo para averiguar a significância das correlações globais nos primeiros eixos de ordenação. As análises estatísticas foram realizadas no programa CANOCO (versão 4.51, 2003).

\section{RESULTADOS E DISCUSSÃO}

\section{Fitossociologia}

A área amostrada representou 9\% da Mata do Desamparo. Foram amostrados 1760 indivíduos arbóreos, distribuídas em 94 espécies e 39 famílias botânicas (Tabela 1). A área basal amostrada foi de $20,93 \mathrm{~m}^{2} \mathrm{ha}^{-1}$ (Tabela 1). As famílias com maior riqueza de espécies foram Fabaceae (8), Myrtaceae (7) e Lauraceae (7) e o índice de diversidade de Shannon para espécies foi de 3,37.

Em comparação com outras florestas estacionais semideciduais da região, a densidade de indivíduos foi considerada alta e superior a outros trabalhos em florestas estacionais no Triângulo Mineiro com o mesmo critério amostral, cuja maioria possuiu menos de 1000 árvores por hectare (ARAÚJO; GUIMARÃES; NAKAJIMA, 1997; LOPES et al., 2012). Grandes adensamentos de árvores podem ocorrer em áreas perturbadas quando os impactos dificultam o estabelecimento de árvores de grande porte que apresentam crescimento lento (VALE et al., 2009). No entanto, florestas ocorrentes em gradientes de fertilidade, inundações periódicas e declividade do solo podem aumentar a heterogeneidade local (CARDOSO; SCHIAVINI, 2002) e possuir mais do que 1500 indivíduos (RODRIGUEZ-SOUZA et al., 2015). Cerradões, por exemplo, tendem a possuir maior adensamento de indivíduos, enquanto que florestas estacionais tendem a ter maior quantidade de árvores de maior porte, o que reduz a densidade por hectare (OLIVEIRA et al., 2014).

Além disso, a ocorrência de espécies tanto típicas de cerradão, quanto de florestas estacionais e florestas ciliares (Tabela 1) auxiliam a aumentar a riqueza, tendo efeitos na diversidade. O índice de diversidade de Shannon, de 3,45 está dentro do intervalo de 3,16 a 4,29 apresentado por Leitão Filho (1987) para diferentes florestas estacionais semideciduais no Estado de São Paulo e também para florestas do Triangulo Mineiro, que variou entre 2,92 e 3,90 em 10 áreas de florestas semideciduais (LOPES et al., 2012).

Em relação à área basal, a floresta estudada apresentou um dos valores mais baixos em comparação com diversos outros trabalhos em florestas estacionais (LOPES et al., 2012), apenas superior a uma área altamente impactada (GUSSON et al., 2009) e também inferior a cerradões da região (RODRIGUES; ARAÚJO, 2013). Este parece ser um dos maiores indicadores do atual estádio de sucessão da floresta. Florestas com elevada densidade de indivíduos e baixa área basal são indicadores de estágios iniciais de sucessão florestal (MACHADO; OLIVEIRA-FILHO, 2010). É também provável que os impactos prévios ocorridos na floresta como introdução de espécies exóticas, presença de gado doméstico e, principalmente, retirada de madeira tenham contribuído para o atual estádio mais inicial de sucessão. A retirada de madeira tem efeitos particularmente negativos para muitas espécies florestais, pois a retirada de grandes árvores abre clareiras no dossel aumentando a luminosidade no sub-bosque, favorecendo o crescimento de espécies demandantes de luz como plantas pioneiras (VALE et al., 2009). Nestes casos, espécies de crescimento rápido, frequentemente de pequeno porte, tendem a ocupar o espaço deixado pelos indivíduos mortos formando adensamentos de pequenas árvores. Além disso, algumas espécies mais típicas de bordas florestais e comumente encontradas em áreas de cerrado sensu stricto foram amostradas, ou seja, espécies demandantes de luz solar intensa para seu estabelecimento têm colonizado o bosque como Byrsonima laxiflora, além de diversas espécies do gênero Miconia, além de Xylopia aromatica.

As dez espécies com maior valor de importância sumarizaram 53,36\% do valor de importância e algumas apresentaram alta densidade como Licania kunthiana, Tapirira obtusa, Inga sessilis, Casearia 
TABELA 1: Estrutura fitossociológica do estrato arbóreo do fragmento florestal do Parque Municipal da Mata do Desamparo, Araguari - MG, organizada em ordem decrescente de VI. Números sobrescritos indicam em qual fitofisionomia a espécie teve densidade superior a $50 \%$ e quando em nenhuma fitofisionomia a espécie obteve tal valor, foi considerada generalista (análise realizada apenas para as espécies que foram utilizadas na CCA)

TABLE 1: Arboreal phytosociological structure of Mata do Desamparo Municipal City Park, Araguari, MG state, in decreasing of VI. Superscript numbers indicate the vegetation type where the species had density greater than $50 \%$ and when any phytophysiognomy species obtained such value, was considered general.

\begin{tabular}{|c|c|c|c|c|c|c|}
\hline Espécie & Família & $\mathrm{N}$ & DR & DoR & FR & VI \\
\hline Licania kunthiana Hook. f. ${ }^{2}$ & Chrysobalanaceae & 365 & 20,74 & 14,92 & 5,92 & 41,58 \\
\hline Tapirira obtusa (Benth.) D.J. Mitch. ${ }^{4}$ & Anacardiaceae & 139 & 7,90 & 10,87 & 4,94 & 23,70 \\
\hline Inga sessilis (Vell.) Mart. ${ }^{1}$ & Fabaceae & 161 & 9,15 & 6,60 & 5,78 & 21,53 \\
\hline Casearia grandiflora Cambess. ${ }^{2}$ & Salicaceae & 142 & 8,07 & 2,98 & 5,36 & 16,41 \\
\hline Mortas & & 62 & 3,52 & 4,33 & 4,80 & 12,65 \\
\hline Ocotea spixiana (Nees)Mez. ${ }^{4}$ & Lauraceae & 26 & 1,48 & 7,40 & 2,54 & 11,42 \\
\hline Siparuna guianensis Aubl. ${ }^{4}$ & Siparunaceae & 94 & 5,34 & 1,29 & 4,23 & 10,87 \\
\hline Virola sebifera Aubl. ${ }^{4}$ & Myristicaceae & 57 & 3,24 & 1,91 & 4,80 & 9,94 \\
\hline Copaifera langsdorffii Desf ${ }^{4}$ & Fabaceae & 17 & 0,97 & 5,33 & 2,26 & 8,56 \\
\hline Maprounea guianensis Aubl. ${ }^{2}$ & Euphorbiaceae & 42 & 2,39 & 3,32 & 2,40 & 8,10 \\
\hline Cordiera sessilis (Vell.) Kuntze. ${ }^{3}$ & Rubiaceae & 62 & 3,52 & 1,62 & 2,82 & 7,96 \\
\hline Astronium fraxinifolium Schott ex Spreng. ${ }^{4}$ & Anacardiaceae & 41 & 2,33 & 1,44 & 3,67 & 7,44 \\
\hline Matayba guianensis Aubl. ${ }^{4}$ & Sapindaceae & 36 & 2,05 & 1,40 & 3,10 & 6,55 \\
\hline Callisthene major Mart. $^{3}$ & Vochysiaceae & 25 & 1,42 & 3,28 & 1,83 & 6,54 \\
\hline Apuleia leiocarpa (Vogel) Macbr. ${ }^{4}$ & Fabaceae & 24 & 1,36 & 1,97 & 2,26 & 5,59 \\
\hline Tapirira guianensis Aubl. ${ }^{1}$ & Anacardiaceae & 29 & 1,65 & 2,66 & 1,27 & 5,58 \\
\hline Calophyllum brasiliense Cambess. ${ }^{1}$ & Clusiaceae & 13 & 0,74 & 3,02 & 0,85 & 4,61 \\
\hline Terminalia glabrescens Mart. $^{3}$ & Combretaceae & 28 & 1,59 & 1,18 & 1,83 & 4,60 \\
\hline Cheiloclinium cognatum (Miers.)A. DC. ${ }^{3}$ & Celastraceae & 22 & 1,25 & 1,04 & 1,69 & 3,98 \\
\hline Styrax camporum Pohl $^{4}$ & Styracaceae & 15 & 0,85 & 1,08 & 1,97 & 3,90 \\
\hline Ocotea corymbosa (Meisn.) Mez & Lauraceae & 6 & 0,34 & 2,77 & 0,71 & 3,82 \\
\hline Protium heptaphyllum (Aubl.) Marchal ${ }^{1}$ & Burseraceae & 19 & 1,08 & 1,31 & 1,41 & 3,80 \\
\hline Byrsonima laxiflora Griseb. ${ }^{4}$ & Malphiguiaceae & 17 & 0,97 & 0,48 & 1,83 & 3,28 \\
\hline Myracrodruon urundeuva Fr. Allem. ${ }^{3}$ & Anacardiaceae & 18 & 1,02 & 0,68 & 1,55 & 3,26 \\
\hline Xylopia emarginata Mart. ${ }^{1}$ & Anacardiaceae & 18 & 1,02 & 0,77 & 0,85 & 2,64 \\
\hline Heisteria ovata Benth. $^{3}$ & Olacaceae & 17 & 0,97 & 0,50 & 1,13 & 2,60 \\
\hline Micropholis venulosa Pierre. $^{1}$ & Sapotaceae & 15 & 0,85 & 0,38 & 1,27 & 2,50 \\
\hline Cassia ferruginea Schrad. ex DC. & Fabaceae & 2 & 0,11 & 2,01 & 0,28 & 2,41 \\
\hline Xylopia aromatica (Lam.) Mart. $^{2}$ & Anacardiaceae & 13 & 0,74 & 0,37 & 1,27 & 2,38 \\
\hline Luehea grandiflora Mart. $^{3}$ & Malvaceae & 11 & 0,63 & 0,44 & 1,13 & 2,19 \\
\hline Nectandra membranacea (Sw.) Griseb. & Lauraceae & 8 & 0,45 & 0,88 & 0,85 & 2,18 \\
\hline Myrcia splendens (Sw.)Dc. ${ }^{3}$ & Myrtaceae & 10 & 0,57 & 0,24 & 1,27 & 2,08 \\
\hline Duguetia lanceolata St. Hilaire ${ }^{4}$ & Annonaceae & 10 & 0,57 & 0,20 & 1,13 & 1,90 \\
\hline Aniba heringeri Vattimo. ${ }^{1}$ & Lauraceae & 14 & 0,80 & 0,34 & 0,71 & 1,84 \\
\hline Pouteria torta (Mart.) Radlk. & Sapotaceae & 8 & 0,45 & 0,33 & 0,99 & 1,78 \\
\hline
\end{tabular}


TABELA 1: Continuação...

TABLE 1: Continued...

\begin{tabular}{|c|c|c|c|c|c|c|}
\hline Espécie & Família & $\mathrm{N}$ & DR & DoR & FR & VI \\
\hline Casearia sylvestris $\mathrm{Sw}$. & Salicaceae & 6 & 0,34 & 0,67 & 0,71 & 1,71 \\
\hline Calyptranthes lucida Mart.ex DC. & Myrtaceae & 8 & 0,45 & 0,27 & 0,99 & 1,71 \\
\hline Eriotheca candolleana (K. Schum.) A. Rob. & Malvaceae & 4 & 0,23 & 0,84 & 0,56 & 1,64 \\
\hline Aspidosperma discolor A. DC. & Apocynaceae & 8 & 0,45 & 0,31 & 0,85 & 1,61 \\
\hline Hedyosmum brasiliense Mart. ex Miq. & Chloranthaceae & 9 & 0,51 & 0,20 & 0,85 & 1,56 \\
\hline Richeria grandis Vahl & Phyllanthaceae & 6 & 0,34 & 0,64 & 0,56 & 1,55 \\
\hline Cecropia pachystachya Trécul $^{1}$ & Urticaceae & 12 & 0,68 & 0,34 & 0,42 & 1,45 \\
\hline Coussarea hydrangeifolia (Benth.) Müll.Arg. & Rubiaceae & 7 & 0,40 & 0,15 & 0,71 & 1,25 \\
\hline Miconia ibaguensis Triana & Melastomataceae & 4 & 0,23 & 0,43 & 0,56 & 1,22 \\
\hline Ficus enormis (Mart. ex Miq.) Miq. & Moraceae & 6 & 0,34 & 0,31 & 0,56 & 1,22 \\
\hline Ixora brevifolia Benth. & Rubiaceae & 7 & 0,40 & 0,34 & 0,42 & 1,16 \\
\hline Handroanthus sp. & Bignoniaceae & 1 & 0,06 & 0,93 & 0,14 & 1,12 \\
\hline Cryptocarya aschersoniana Mez. & Lauraceae & 2 & 0,11 & 0,70 & 0,28 & 1,10 \\
\hline Alchornea glandulosa Poepp. \& Endl. & Euphorbiaceae & 2 & 0,11 & 0,67 & 0,28 & 1,07 \\
\hline Ouratea castaneifolia (DC.) Engl. & Ochnaceae & 4 & 0,23 & 0,23 & 0,56 & 1,02 \\
\hline Eugenia florida DC. & Myrtaceae & 6 & 0,34 & 0,10 & 0,56 & 1,00 \\
\hline Cordia sellowiana Cham. & Boraginaceae & 5 & 0,28 & 0,12 & 0,56 & 0,97 \\
\hline Cardiopetalum calophyllum Schltdl. & Annonaceae & 4 & 0,23 & 0,15 & 0,56 & 0,94 \\
\hline Hymenaea courbaril $\mathrm{L}$. & Fabaceae & 4 & 0,23 & 0,28 & 0,42 & 0,93 \\
\hline Diospyros hispida A.DC. & Ebenaceae & 5 & 0,28 & 0,22 & 0,42 & 0,93 \\
\hline Hirtella glandulosa Spreng. & Chrysobalanaceae & 2 & 0,11 & 0,51 & 0,28 & 0,91 \\
\hline Siphoneugena densiflora O.Berg. & Myrtaceae & 3 & 0,17 & 0,26 & 0,42 & 0,85 \\
\hline Licania humilis Cham. \& Schltdl. & Chrysobalanaceae & 5 & 0,28 & 0,14 & 0,42 & 0,84 \\
\hline Syzygium jambos (L.) Alston * & Myrtaceae & 4 & 0,23 & 0,16 & 0,42 & 0,81 \\
\hline Terminalia phaeocarpa Eichler. & Combretaceae & 3 & 0,17 & 0,16 & 0,42 & 0,75 \\
\hline Croton sp. & Euphorbiaceae & 3 & 0,17 & 0,15 & 0,28 & 0,60 \\
\hline Senegalia polyphylla (DC.)Britton \& Rose. & Fabaceae & 2 & 0,11 & 0,19 & 0,28 & 0,59 \\
\hline Maytenus floribunda Reissek. & Celastraceae & 3 & 0,17 & 0,05 & 0,28 & 0,51 \\
\hline Agonandra brasiliensis Miers ex Benth. & Opiliaceae & 2 & 0,11 & 0,10 & 0,28 & 0,50 \\
\hline Hirtella gracilipes (Hook.f.) Prance. & Chrysobalanaceae & 2 & 0,11 & 0,06 & 0,28 & 0,45 \\
\hline Aspidosperma cylindrocarpon Müll.Arg. & Apocynaceae & 2 & 0,11 & 0,04 & 0,28 & 0,44 \\
\hline Ocotea minarum (Nees \& Mart.) Mez. & Lauraceae & 2 & 0,11 & 0,03 & 0,28 & 0,43 \\
\hline Schefflera morototoni (Aubl.) Maguire & Araliaceae & 1 & 0,06 & 0,23 & 0,14 & 0,43 \\
\hline Euplassa sp. & Proteaceae & 2 & 0,11 & 0,03 & 0,28 & 0,43 \\
\hline Bauhinia holophylla (Bong.) Steud & Fabaceae & 2 & 0,11 & 0,03 & 0,28 & 0,42 \\
\hline Pseudolmedia laevigata Trécul. & Moraceae & 2 & 0,11 & 0,02 & 0,28 & 0,42 \\
\hline Trichilia sp. & Meliaceae & 1 & 0,06 & 0,08 & 0,14 & 0,28 \\
\hline Cabralea canjerana (Vell.) Mart. & Meliaceae & 1 & 0,06 & 0,04 & 0,14 & 0,24 \\
\hline Miconia sellowiana Naudin. & Melastomataceae & 1 & 0,06 & 0,03 & 0,14 & 0,23 \\
\hline Erythroxylum daphnites Mart. & Erythroxylaceae & 1 & 0,06 & 0,03 & 0,14 & 0,23 \\
\hline Machaerium acutifolium Vogel. & Fabaceae & 1 & 0,06 & 0,03 & 0,14 & 0,23 \\
\hline
\end{tabular}


TABELA 1: Continuação...

TABLE 1: Continued...

\begin{tabular}{|c|c|c|c|c|c|c|}
\hline Espécie & Família & $\mathrm{N}$ & $\mathrm{DR}$ & DoR & FR & VI \\
\hline Qualea dichotoma (Mart.) Warm. & Vochysiaceae & 1 & 0,06 & 0,03 & 0,14 & 0,23 \\
\hline Pouteria gardneri (Mart. \& Miq.) Baehni. & Sapotaceae & 1 & 0,06 & 0,03 & 0,14 & 0,23 \\
\hline Cordia trichotoma (Vell.) Arráb. ex Steud. & Boraginaceae & 1 & 0,06 & 0,03 & 0,14 & 0,23 \\
\hline Apeiba tibourbou Aubl. & Malvaceae & 1 & 0,06 & 0,03 & 0,14 & 0,22 \\
\hline Myrcia tomentosa (Aubl.) DC. & Myrtaceae & 1 & 0,06 & 0,03 & 0,14 & 0,22 \\
\hline Nectandra cissiflora Nees. & Lauraceae & 1 & 0,06 & 0,02 & 0,14 & 0,22 \\
\hline Piper arboreum Aubl. & Piperaceae & 1 & 0,06 & 0,02 & 0,14 & 0,22 \\
\hline Miconia cuspidata Naud. & Melastomataceae & 1 & 0,06 & 0,02 & 0,14 & 0,22 \\
\hline Miconia albicans (Sw.) Triana. & Melastomataceae & 1 & 0,06 & 0,02 & 0,14 & 0,22 \\
\hline $\begin{array}{l}\text { Handroanthus serratifolius (A.Hgentry) S. } \\
\text { Grose. }\end{array}$ & Bignoniaceae & 1 & 0,06 & 0,02 & 0,14 & 0,21 \\
\hline Guettarda viburnoides Cham. \& Schltdl. & Rubiaceae & 1 & 0,06 & 0,02 & 0,14 & 0,21 \\
\hline Trichilia pallida $\mathrm{Sw}$. & Meliaceae & 1 & 0,06 & 0,02 & 0,14 & 0,21 \\
\hline Cupania vernalis Cambess. & Sapindaceae & 1 & 0,06 & 0,01 & 0,14 & 0,21 \\
\hline Ouratea spectabilis (Mart.) Engl. & Ochnaceae & 1 & 0,06 & 0,01 & 0,14 & 0,21 \\
\hline Psidium rufum Mart. ex DC. & Myrtaceae & 1 & 0,06 & 0,01 & 0,14 & 0,21 \\
\hline Miconia chamissois Naudin. & Melastomataceae & 1 & 0,06 & 0,01 & 0,14 & 0,21 \\
\hline Pera glabrata (Schott) Poepp. ex Baill. & Peraceae & 1 & 0,06 & 0,01 & 0,14 & 0,21 \\
\hline $\begin{array}{l}\text { Garcinia gardneriana (Planch. \& Triana) } \\
\text { Zappi. }\end{array}$ & Clusiaceae & 1 & 0,06 & 0,01 & 0,14 & 0,21 \\
\hline Lacistema aggregatum (P.J.Bergius) Rusby. & Lacistemataceae & 1 & 0,06 & 0,01 & 0,14 & 0,21 \\
\hline
\end{tabular}

Em que: $\mathrm{N}=$ número de indivíduos; $\mathrm{DR}=$ Densidade Relativa; DoR = Dominância Relativa; $\mathrm{FR}=$ Frequência Relativa e VI = Valor de Importância. Densidade proporcional superior a 50\% nos blocos com determinada fitofisionomia: $1=$ Floresta de galeria, 2 = Floresta semidecidual, 3 = Cerradão, $4=$ Generalista (nas três fisionomias), *espécie exótica.

grandiflora e Siparuna guianensis (Tabela 1). Além destas espécies, Virola sebifera, foi amostrada em pelo menos 21 das 25 parcelas e possuiu alta frequência relativa (Tabela 1). Licania kunthiana e Casearia grandiflora (duas espécie arbóreas de pequeno porte, porém, com elevada densidade) e Tapirira obtusa, Ocotea spixiana e Inga sessilis (três espécies comumente encontradas em dosséis por apresentarem indivíduos de grande porte) possuíram elevada dominância relativa. Das espécies mais densas na área, três apresentaram densidade proporcional por parcela superior a 50\% no bloco mais próximo ao córrego (bloco 1 - Tabela 1), três nos blocos intermediários (blocos 2 e 3), quatro no bloco mais distante do córrego (bloco 4) e nove não obtiveram valores superiores a $50 \%$ de indivíduos e foram classificadas como generalistas na área (Tabela 1), sete ocorreram em todos os blocos amostrados. Logo, parte da elevada riqueza e diversidade pode ser explicada pela presença desde espécies comuns de ambientes inundados ou alagáveis devido à proximidade do leito do rio verificada nas parcelas localizadas na mata de galeria, como Cecropia pachystachya, Protium heptaphyllum, Inga sessilis, Calophyllum brasiliense e Xylopia emarginata, até espécies mais características de solos bem drenados, como Terminalia glabrescens, Cheiloclinium cognatum e Myracroduron urundeuva. É reconhecido que pequenas variações na umidade do solo podem provocar mudanças no estabelecimento das espécies (NILSSON, 1996; VALE et al., 2013).

Os dados gerais das análises de solo das parcelas estão sumarizados na Tabela 2, contudo, houve grande variação entre os blocos de parcelas amostrados. A umidade do solo apresentou alta variação nas quatro profundidades avaliadas (Tabela 2). Apesar desta variação, as médias de umidade foram semelhantes (Tabela 2). Quanto ao desnível, houve desde parcelas sem qualquer desnível até parcelas com $11^{\circ}$ de declividade. $\mathrm{O}$ pH do solo foi ácido, variando de 4,10 a 5,10 e as demais variáveis de solo demonstraram 
TABELA 2: Variáveis topográficas, edáficas, análises de variância (ANOVA) entre os blocos amostrais e Teste a posteriori de Tukey, comparando-se os blocos do fragmento florestal inserido no Parque Municipal da Mata do Desamparo, Araguari - MG. Letras representam diferenças entres os blocos cujas letras iniciais do alfabeto demonstram valores maiores. V = saturação por bases, $\mathrm{m}=$ saturação por Al. *Variáveis utilizadas na Análise de Correlação Canônica $(\mathrm{n}=25)$.

TABLE 2: Topographic and soil variables, one way analisys of variance (ANOVA) between block samples and a posteriori test comparing blocks in the forest fragment located at the under Mata do Desamparo Muncipal City Park forest fragment, Araguari, MG state. Bigger letters represent higher values. $\mathrm{V}=$ base saturation, $\mathrm{m}=$ saturation of aluminion. * Variables used in Canonical Correlation Analysis $(\mathrm{n}=25)$.

\begin{tabular}{|c|c|c|c|c|c|c|c|c|c|}
\hline & \multirow[b]{2}{*}{ Profundidade } & \multirow[b]{2}{*}{ Média } & \multirow[b]{2}{*}{ Desv Pad } & \multicolumn{2}{|c|}{ ANOVA } & \multicolumn{4}{|c|}{ Tukey } \\
\hline & & & & $\mathrm{F}$ & $\mathrm{p}$ & Blocol & Bloco2 & Bloco3 & Bloco4 \\
\hline \multirow{4}{*}{ Umidade do solo (\%) } & $0-10 \mathrm{~cm}$ & 17,08 & 3,17 & 2.999 & 0.054 & $18.09 \mathrm{a}$ & $14.37 \mathrm{a}$ & $18.45 \mathrm{a}$ & $17.85 \mathrm{a}$ \\
\hline & $50-60 \mathrm{~cm}$ & 17,03 & 3,76 & 5.003 & 0.009 & $20.68 \mathrm{a}$ & $15.48 \mathrm{~b}$ & $17.79 \mathrm{a}$ & $14.41 \mathrm{~b}$ \\
\hline & $100-110 \mathrm{~cm}$ & 19,41 & 6,93 & 5.688 & 0.005 & $27.37 \mathrm{a}$ & $15.77 \mathrm{~b}$ & $17.09 \mathrm{~b}$ & $18.04 \mathrm{~b}$ \\
\hline & $150-160 \mathrm{~cm} *$ & 19,26 & 7,34 & 4.417 & 0.015 & $27.06 \mathrm{a}$ & $15.49 \mathrm{~b}$ & $17.15 b$ & $17.97 \mathrm{a}$ \\
\hline Topografia & Desnível (graus)* & 6,14 & 3,33 & 75.100 & 0.000 & $1.65 \mathrm{~d}$ & $5.04 \mathrm{c}$ & $7.92 b$ & $10.12 \mathrm{a}$ \\
\hline \multirow{8}{*}{$\begin{array}{l}\text { Características } \\
\text { químicas }\end{array}$} & $\mathrm{pH}\left(\mathrm{H}_{2} \mathrm{O}\right)$ & 4,51 & 0,24 & 14.520 & 0.000 & $4.75^{\mathrm{a}}$ & $4.23 \mathrm{~b}$ & $4.58 \mathrm{a}$ & $4.53 \mathrm{a}$ \\
\hline & $\mathrm{P}\left(\mathrm{mg} / \mathrm{dm}^{3}\right)^{*}$ & 1,93 & 0,47 & 6.913 & 0.002 & $2.48^{\mathrm{a}}$ & $1.70 \mathrm{~b}$ & $1.90 \mathrm{~b}$ & $1.67 \mathrm{~b}$ \\
\hline & $\mathrm{K}^{1+}\left(\mathrm{cmol}_{\mathrm{c}} / \mathrm{dm}^{3}\right)$ & 0,11 & 0,02 & 2.090 & 0.132 & $0.12^{\mathrm{a}}$ & $0.10 \mathrm{a}$ & $0.12 \mathrm{a}$ & $0.12 \mathrm{a}$ \\
\hline & $\mathrm{Ca}^{2+}\left(\mathrm{cmol}_{\mathrm{c}} / \mathrm{dm}^{3}\right)$ & 0,35 & 0,36 & 12.310 & 0.000 & $0.84^{\mathrm{a}}$ & $0.09 b$ & $0.22 b$ & $0.30 \mathrm{~b}$ \\
\hline & $\mathrm{Mg}^{2+}\left(\mathrm{cmol}_{\mathrm{c}} / \mathrm{dm}^{3}\right)$ & 0,19 & 0,08 & 3.149 & 0.047 & $0.23^{\mathrm{a}}$ & $0.12 \mathrm{a}$ & $0.22 \mathrm{a}$ & $0.19 \mathrm{a}$ \\
\hline & $\mathrm{Al}^{3+}\left(\mathrm{cmol}_{\mathrm{c}} / \mathrm{dm}^{3}\right)^{*}$ & 1,15 & 0,25 & 5.352 & 0.007 & $0.87 \mathrm{~b}$ & $1.29 \mathrm{a}$ & $1.21 \mathrm{a}$ & $1.21 \mathrm{a}$ \\
\hline & $\mathrm{V} \%$ & 5,72 & 4,27 & 6.204 & 0.003 & $10.6^{\mathrm{a}}$ & $3.14 \mathrm{~b}$ & $5.00 \mathrm{~b}$ & $4.50 \mathrm{~b}$ \\
\hline & $\mathrm{m} \%$ & 64,52 & 21,21 & 4.076 & 0.020 & $46.50 \mathrm{~b}$ & $80.43 a$ & $59.68 \mathrm{~b}$ & $68.83 b$ \\
\hline Matéria orgânica & dag kg-1* & 4,05 & 0,75 & 1.756 & 0.186 & $4.13^{\mathrm{a}}$ & $3.54 \mathrm{a}$ & $4.25 \mathrm{a}$ & $4.37 \mathrm{a}$ \\
\hline
\end{tabular}

Em que: Desv Pad = desvio padrão; $F$ = teste F de Fisher; $p$ = valor de probabilidade. Médias seguidas de mesma letra não diferem significativa entre si.

que a floresta possui solos pouco férteis (V\% menores do que $20 \%$ nas parcelas) com baixos valores de $\mathrm{P}, \mathrm{K}, \mathrm{Ca}$ e matéria orgânica. Além disso, o solo pode ser considerado álico, ou seja, com baixo potencial nutricional, por possuir quantidades de alumínio retido (m) superiores a 50\% (Tabela 2).

A análise de correspondência canônica (CCA) demonstrou que o desnível, matéria orgânica, umidade do solo e teor de fósforo foi o que mais explicou a ocorrência das espécies. O resultado da CCA apresentou alto valor para o eixo um $(0,54)$, porém, baixos para o eixo $2(0,28)$ e para o eixo 3 (pouco explicativo) demonstrando a existência de um gradiente relativamente bem definido para o eixo $1 \mathrm{e}$ curto para o eixo 2 (Figura 2). As variâncias acumuladas para as espécies foram de 31,1\%, 47,3\% e 50,8\%, logo, os dois primeiros eixos explicam aproximadamente $47 \%$ da distribuição das espécies. O teste de Monte Carlo comprovou a correlação significativa entre as espécies e as variáveis ambientais para os três primeiros eixos $(\mathrm{p}<0.001)$, cuja correlação foi de 0,959 para o eixo 1 e 0,889 para o eixo 2 .

O eixo 1 apresentou correlação positiva com umidade do solo e teor de $\mathrm{P}$ e negativa com o desnível (Figura 2) enquanto o eixo 2 apresentou correlação positiva com K e matéria orgânica e negativa com Al. As variáveis ambientais formaram, pelo menos, três grupos. Um deles mais explicado pela umidade do solo e teor de fosforo, formado por Tapirira guianensis, Aniba heringeri, Xylopia emarginata e Cecropia pachystachya, justamente nas parcelas localizadas na mata de galeria (sobretudo nas parcelas 1 a 4 ). $\mathrm{O}$ segundo e o terceiro grupo formam as parcelas localizadas distantes do leito do rio e possuem espécies de florestas secas, cuja grande maioria é generalista. O segundo grupo foi explicado pelos altos valores de desnível, matéria orgânica e teor de K, principalmente nas parcelas 22, 24, 25 (bloco 4) e 18 (bloco 3), formado pelas espécies Myracrodruon urundeuva, Cheiloclinium cognatum, Heisteria ovata, Cordiera sessilis, Terminalia glabrescens, Callistene major, Luehea grandiflora (Figura 2). Já o terceiro grupo foi 
explicado pela presença de Al, formado pelas espécies Casearia grandiflora, Licania kunthiana, Tapirira obtusa e Maprounea guianenses (Figura 2) localizadas no bloco 2 (parcelas 7 a 13). As demais espécies, mesmo que influenciadas pelas variáveis ambientais, foram mais fracamente correlacionadas com estas variáveis e, por isso, deve haver cautela ao inseri-las em algum grupo.
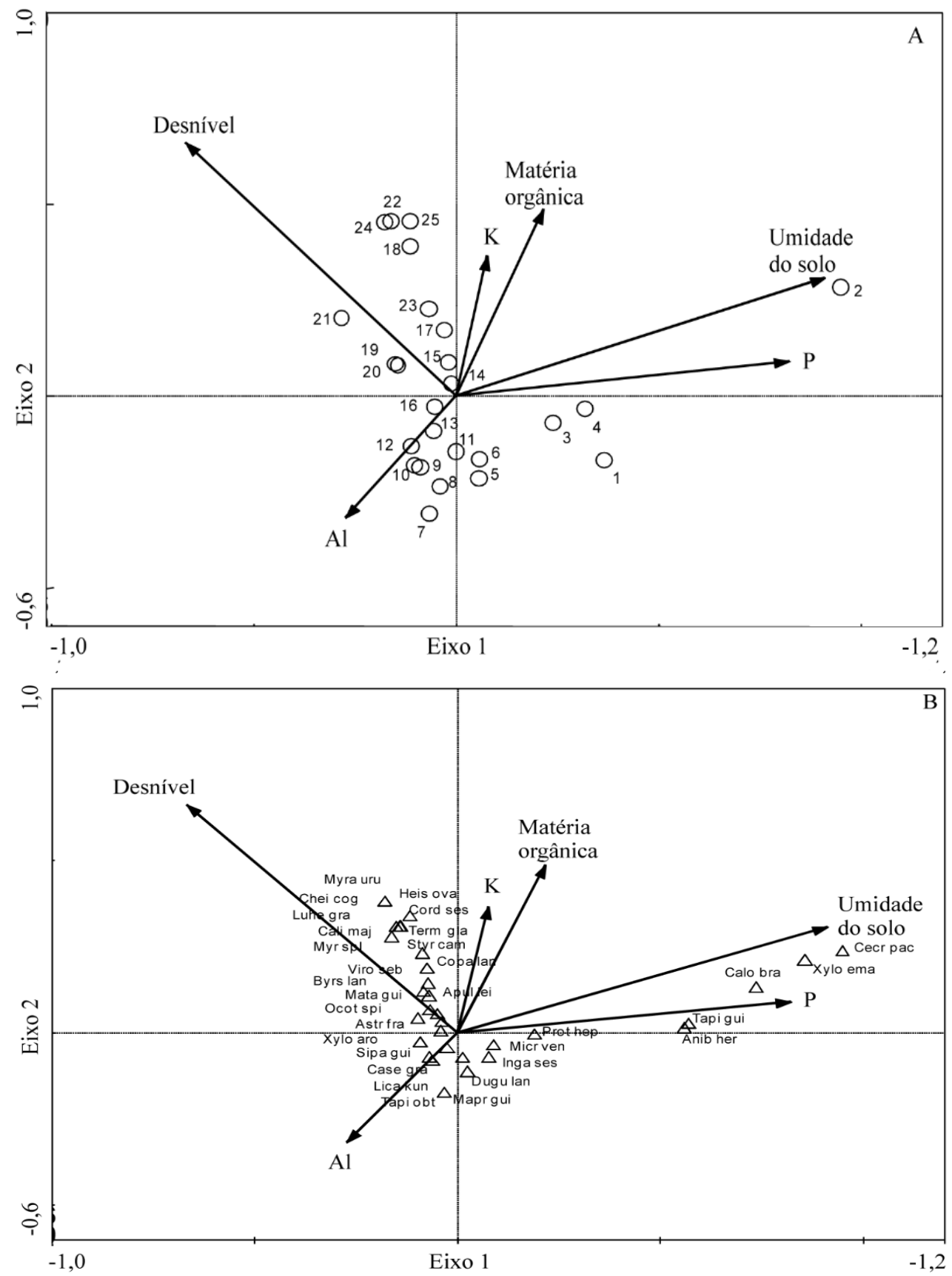

FIGURA 2: Análise de correspondência canônica (CCA): diagramas de ordenação das parcelas (A) e espécies (B) no fragmento florestal do Parque Municipal da Mata do Desamparo, Araguari - MG, e sua correlação com as variáveis do solo. As espécies são indicadas pelo seu nome abreviado (nome completo das espécies na Tabela 1).

FIGURE 2: Canonical Correspondence Analysis (CCA) ordination diagrams to the plots (A) and to the species (B) in Mata do Desamparo Municipal City Park forest fragment, Araguari, MG state, and its correlation with soil variables. Species are indicated by its abbreviated name (full name of the species in Table 1). 
Assim, não foi surpreendente que a umidade do solo tenha sido um dos principais fatores modeladores da distribuição destas espécies, demonstrado pela CCA e já relatado em outros trabalhos (BOTREL et al., 2002; CAMARGOS et al., 2008). As parcelas localizadas mais próximas ao leito do córrego (1 a 4) também possuíram altos valores de fósforo e baixa saturação por alumínio, sendo o solo mais fértil e menos ácido do que as demais parcelas localizadas distantes do curso de água. Outros trabalhos retratam que os teores de macronutrientes diminuem e o solo é mais pobre e ácido distante de cursos de água (BOTREL et al., 2002; MARTINS et al., 2003).

Estas espécies também foram encontradas em áreas de menor declive, o que indica maior capacidade do solo em reter umidade e sedimentos, aumentando os teores de alguns macronutrientes como o fósforo. Áreas em alto declive tendem a escoar a água das chuvas com maior facilidade, retendo menos água e favorecendo espécies de ambiente mais seco, tais quais Myracrodruon urundeuva (considerada especialista de florestas estacionais secas), Luehea grandiflora (considerada generalista de florestas estacionais secas) (LINARES-PALOMINO; OLIVEIRA-FILHO; PENNINGTON, 2011), Myrcia splendens e Callistene major, espécies ocorrentes com elevada frequência em florestas secas (OLIVEIRA-FILHO et al., 2006) e em áreas montanhosas, como florestas deciduais, cuja declividade e o escoamento superficial são elevados (VALE et al., 2010), com baixa retenção de umidade nas partículas de solo. Ainda assim, as três primeiras espécies supracitadas são consideradas "supercomuns" em florestas estacionais (OLIVEIRA-FILHO et al., 2006), logo, a separação de floresta estacional semidecidual para cerradão não foi bem demarcada.

Devido à declividade há locais em que ocorre sedimentação de materiais oriundos da porção superior da comunidade, nos quais a matéria orgânica se acumula. Nestas parcelas, a concentração de alumínio foi menor e os teores de potássio $(\mathrm{K})$ e matéria orgânica foram elevados, o que propiciou condições para espécies se desenvolverem nestes ambientes mais férteis, como Heisteria ovata, Styrax camporum e Myracrodruon urundeuva. Entretanto, o alto teor de alumínio e a baixa concentração de nutrientes em pelo menos 10 parcelas, propiciaram o desenvolvimento de espécies típicas desta condição. Maprounea guianensis é presente em florestas pobres com altas taxas de alumínio (MARTINS et al., 2003), assim como Siparuna guianensis (NASCIMENTO, 2011), e Licania kunthiana (ARAÚJO; GUIMARÃES; NAKAJIMA, 1997). Inclusive Licania kunthiana foi a espécie mais densa e importanteembosquesituadonazona urbanadeAraguari,cujossolospossuemaltataxade saturaçãodealumínio (ARAÚJO; GUIMARÃES; NAKAJIMA, 1997), confirmando seu bom estabelecimento em solos pobres.

Entretanto, apesar das análises apontarem para a formação de grupos de parcelas distintas com algumas espécies principais de cada bloco amostral, grande parte das espécies é considerada generalista de habitat, demonstrando que o ambiente não é característico de uma determinada fitofisionomia. Apesar de ser considerada uma floresta estacional, a área estudada possui uma borda extensa com dossel mais baixo do que aquele apresentado no interior e na beira do córrego. Pode-se considerar, assim, que esta floresta pode possuir trechos de transição de cerradão para floresta estacional (blocos 2,3 e 4 ) e um trecho mais característico de ambientes alagáveis (bloco 1).

Este é um fator extremamente importante para a necessidade de conservação desta área, justamente esta grande variedade de ambientes, desde locais mais úmidos até os mais secos (borda) e com distintos teores de nutrientes. Este gradiente edáfico gera uma grande heterogeneidade ambiental que oferece oportunidades para diferentes espécies, com distintas adaptações a se estabelecerem no ambiente, aumentando a diversidade local e o valor da sua conservação. Preservar grandes áreas naturais é a chave para a preservação da biodiversidade (ALVEY, 2006), entretanto as florestas urbanas, sobretudo as mais heterogêneas e diversas, apesar de pequenos fragmentos têm papel fundamental na permanência de diversos grupos de espécies, como comprovado neste estudo.

Por fim, a área apresenta uma espécie introduzida da Ásia, o Syzygium jambos (popularmente conhecida como jambo) e, apesar de ser uma planta comestível, deve ser manejada. Apesar de apenas quatros indivíduos amostrados, a ocorrência desta espécie pelo parque é comum, e sua colonização nos setores mais conservados da floresta deve ser acompanhado para que esta espécie não invada o local. Espécies introduzidas são o segundo maior problema para a biodiversidade, atrás apenas da conversão de terras naturais para o uso humano (MCNEELY et al., 2001). A prática de introduzir espécies exóticas comestíveis em parques urbanos é comum como no Bosque dos Alemães, Parque Ipê Uberada e Marília, São José da Bela Vista que possuem espécies de amora, mangueira e abacateiro 
(PAGORARI, 2007; ARAÚJO; CARDOSO-LEITE; CHAGAS, 2009; MELO et al., 2011). Espécies de outras regiões comumente não apresentam herbívoros naturais e podem ocupar um determinado ambiente em poucos anos, aumentando o tamanho de suas populações e eliminando espécies nativas. Por esta razão, sugere-se o monitoramento através de estudos populacionais de Syzygium jambos no local.

\section{CONCLUSÃO}

A floresta aparenta estar em boas condições de conservação se forem consideradas a riqueza, a diversidade e a heterogeneidade ambiental presente. Ficou evidente a importância da topografia e umidade do solo para a formação de um gradiente florístico-estrutural, desde a porção mais próxima ao córrego a até as áreas mais elevadas e secas, logo toda esta área, e não somente as mais próximas ao córrego, devem ser conservadas e monitoradas. No entanto, a baixa área basal e elevada densidade indicam que a floresta estudada está avançando nos estádios sucessionais. Sobretudo os impactos antrópicos do passado devem ter modificado muito a área e interferido na manutenção da comunidade arbórea. Assim, algumas medidas em curto prazo devem ser realizadas como o cercamento e controle para conter a entrada de gado doméstico e impedir a retirada clandestina de madeira com maior fiscalização. Este fragmento possui significativo valor de riqueza de espécies e sua manutenção deve ser prioritária no município de Araguari.

\section{REFERÊNCIAS}

ALVEY, A. A. Promoting and preserving biodiversity in the urban forest. Urban Forestry \& Urban Greening, Philidelphia, v. 5, n. 4, p. 195-201, 2006.

ANGIOSPERM PHYLOGENY GROUP. An update of the angiosperm phylogeny group, classification for the order and families of flowering plants: APG III. Botanical Journal of the Linnean Society, London, v. 161, p. 105-121, 2009.

ARAÚJO, G. M.; GUIMARÃES, A. J. M.; NAKAJIMA, J. M. Fitossociologia de um remanescente de mata mesófila semidecídua urbana, Bosque John Kennedy, Araguari, MG, Brasil. Revista Brasileira de Botânica, São Paulo, v. 20, n. 1, p. 67-77, 1997.

ARAÚJO, M. H. T.; CARDOSO-LEITE, E.; CHAGAS, E. P. Os fragmentos florestais urbanos do campus da UNIFEOB (São João da Boa Vista - SP): uma abordagem qualitativa como proposta para conservação e manejo. REVSBAU, Piracicaba, v. 4, n. 3, p. 49-68, 2009.

BADIRU, A. I.; PIRES, M. A.; RODRIGUEZ, A. M. Método para classificação tipológica da floresta urbana visando o planejamento e a gestão de cidades. In: SIMPÓSIO BRASILEIRO DE SENSORIAMENTO REMOTO, 12., Goiânia. Anais... [s. 1.: s. n.], 2005. p. 1427-1433.

BOTREL, R. T. et al. Composição florística e estrutura da comunidade arbórea de um fragmento de floresta estacional semidecidual em Ingaí, MG, e a influência de variáveis ambientais na distribuição das espécies. Revista Brasileira de Botânica, São Paulo, v. 25, n. 2, p. 195-213, 2002.

CAMARGOS, V. L. et. al. Influência de fatores edáficos sobre variações florísticas na Floresta Estacional Semidecídua no entorno da Lagoa Carioca, Parque Estadual do Rio Doce, MG, Brasil. Acta botanica brasilica, São Paulo, v. 22, n. 1, p. 75-84, 2008.

CARDOSO, E.; SCHIAVINI, I. Relação entre distribuição de espécies arbóreas e topografia em um gradiente florestal na Estação Ecológica do Panga (Uberlândia, MG). Revista Brasileira de Botânica, São Paulo, v. 25, p. 537-544, 2002.

CAUSTON, D. R. Introduction to vegetation analysis. London: Unwin Hyman, 1998. 342 p.

CIELO-FILHO, R.; SANTIN, D. A. Estudo florístico e fitossociológico de um fragmento florestal urbano -Bosque dos Alemães, Campinas, SP. Revista Brasileira de Botânica, São Paulo, v. 25, n. 3, p. 291-301, 2002.

EMBRAPA. Manual de métodos de análise do solo. Rio de Janeiro: Ministério de agricultura e do abastecimento, 1997.

FELFILI, J. M.; CARVALHO, F. A.; HAIDAR, R. F. Manual para o monitoramento de parcelas permanentes nos Biomas Cerrado e Pantanal. Brasília: Universidade de Brasília, Departamento de Engenharia Florestal, 2005. $51 \mathrm{p}$. 
GUILHERME, F. A. G. et. al. Fitofisionomias e a flora lenhosa nativa do Parque do Sabiá, Uberlândia, MG. Daphne, Belo Horizonte, v. 8, n. 2, p. 17-30, 1998.

GUILHERME, F. A. G.; NAKAJIMA, J. N. Estrutura da vegetação arbórea de um remanescente ecotonal urbano floresta-savana no Parque do Sabiá, Uberlândia, MG. Revista Árvore, Viçosa, MG, v. 31, p. 329-338, 2007.

GUSSON, A. E. et. al. Características químicas do solo e estrutura de um fragmento de floresta estacional semidecidual em Ipiaçu, Minas Gerais, Brasil. Rodriguésia, Rio de Janeiro, v. 60, n. 2, p. 403-414, 2009.

IBGE. Manual Técnico da Vegetação Brasileira. Rio de Janeiro: Ministério do Planejamento, Orçamento e Gestão; IBGE, 2012. 271 p.

KENT, M.; COKER, P. Vegetation description and analysis, a practical approach. London: Belhaven Press, $1992.363 \mathrm{p}$.

LEITÃO FILHO, H. F. Considerações sobre a florísticade florestas trópicas e subtropicais do Brasil. Scientia Florestalis, Piracicaba, n. 35, p. 41-46, 1987.

LINARES-PALOMINO, R.; OLIVEIRA-FILHO, A. T.; PENNINGTON, R. T. Neotropical seasonally dry forests: diversity, endemism, and biogeography of woody plants. In: DIRZO, R. et al. (Ed.). Seasonally dry tropical forests: ecology and conservation. Washington: Island Press, 2011. p. 407.

LOPES, S. F. et. al. An ecological comparison of floristic composition in seasonal semideciduous forest in southeast Brazil: implications for conservation. International Journal of Forestry Research, New York, v. 2012, p. 1-14, 2012.

MACHADO, E. L. M.; OLIVEIRA-FILHO, A. T. Spatial patterns of tree community dynamics are detectable in a small (4 ha) and disturbed fragment of the Brazilian Atlantic forest. Acta Botanica Brasilica, São Paulo, v. 24, n. 1, p. 250-261, 2010.

MARTINS, S. V. et. al. Distribuição de espécies arbóreas em um gradient topográfico de floresta estacional semidecidual em Viçosa, MG. Scientia Florestalis, Piracicaba, n. 64, p. 172-181, 2003.

MCNEELY, J. A. et al. A global strategy on invasive alien species. Cambridge: Global Invasive Species Programme, 2001.

MELO, A. G. C. et. al. Floristica da comunidade arbóreo-arbustiva de um fragmento florestal urbano Bosque Municipal Rangel Pietraróia, Marília, SP. Revista Científica Eletrônica de Engenharia Florestal, Garça, v. 18, n. 1, p. 105-117, 2011.

NILSSON, C. Remediating river margin vegetation along fragmented and regulated rivers in the North: what is possible? Regulated Rivers-Research \& Management, Hoboken, v. 12, p. 415-431, 1996.

NASCIMENTO, M. S. Ecologia funcional e padrões de alocação de alumínio e nutrientes em plantas lenhosas do cerrado. 2011. Dissertação (Mestrado em Botânica) - Universidade Federal de Viçosa, Viçosa, MG, 2011.

OLIVEIRA, A. P. et al. Mortality, recruitment and growth of the tree communities in three forest formations at the Panga Ecological Station over ten years (1997-2007). Acta Botanica Brasilica, Feira de Santana, v. 28, n. 2, p. 234-248, 2014.

OLIVEIRA-FILHO, A. T. et. al. Differentiation of streamside and upland vegetation in an area of montane semideciduous forest in southeastern Brazil. Flora, Jena, v. 189, p. 287-305, 1994.

OLIVEIRA-FILHO, A. T. et al. Floristic relationships of seasonally dry forests of eastern South America based on tree species distribution patterns. In: PENNINGTON, R. T.; LEWIS, G. P.; RATTER, J. A. (Ed.). Neotropical savannas and dry forests: plant diversity, biogeography and conservation. Oxford: Taylor \& Francis, 2006. p. 59-192.

PEGORARI, P. O. Fitossociologia de três fragmentos florestais urbanos de Uberaba, Minas Gerais. Dissertação (Mestrado) - Universidade Federal de Uberlândia, Uberlândia, 2007.

RAMOS, A. J. K.; BOLDO, E. Diversidade florística e aspectos fitossociológicos de formações florestais em estágio sucessional secundário na Floresta Ombrófila Mista, município de Caxias do Sul - RS. Revista Brasileira de Agroecologia, Cruz Alta, v. 2, n. 1, p. 111-116, 2007.

RODRIGUES, R. F.; ARAÚJO, G. M. Estrutura da vegetação e características edáficas de um cerradão em solo distrófico e em solo mesotrófico no Triângulo Mineiro. Bioscience Journal, Uberlândia, v. 29, n. 6, p. 2013-2029, 2013.

RODRIGUES-SOUZA, J. et al. Secondary forest expansion over a savanna domain at an ecological 
reserve in the Southeastern Brazil after 15 years of monitoring. Brazilian Journal of Botany, São Paulo, v. 38. n. 2, p. 311-322, 2015.

ROSA, A. G.; SCHIAVINI, I. Estrutura da comunidade arbórea em um remanescente florestal urbano (Parque do Sabiá, Uberlândia, MG). Bioscience Journal, Uberlândia, v. 22, p. 151-162, 2006.

SANTOS, E. R.; ASSUNÇÃO, W. L. Distribuição espacial das chuvas na microbacia do Córrego do Amanhece, Araguari-MG. Caminhos de Geografia, Uberlândia, v. 7, n. 19, p. 41-55, 2006.

SALLES, J. C.; SCIHIAVINI, I. Estrutura e composição do estrato de regeneração em um fragmento florestal urbano: implicações para a dinâmica e a conservação da comunidade arbórea. Acta Botanica Brasílica, São Paulo, v. 21, n. 1, p. 223-233, 2007.

SANTIN, D. A. A vegetação remanescente do município de Campinas (SP): mapeamento, caracterização fisionômica e florística, visando a conservação. 1999. 199 f. Tese (Doutorado em Ciências Biológicas) Universidade Estadual de Campinas, Campinas, 1999.

SHEPHERD, G. J. FITOPAC-SHELL 1.6.4. Campinas: Universidade Estadual de Campinas, 2004.

SIQUEIRA, J. C. Fundamentos de uma biogeografia para o espaço urbano. Pesquisas, Botânica, São Leopoldo, v. 59, p. 191-210, 2008.

VALE, V. S. et. al. Fast changes in seasonal forest communities due to soil moisture increase after damming. International Journal of Tropical Biology, San José, v. 61, p. 1901-1917, 2013.

VALE, V. S. et. al. Floristic composition and structure of the tree component in a remnant of primary forest in semideciduous Araguari, Minas Gerais, Brazil. Hoehnea, Água Funda, v. 36, n. 2, p. 417-429, 2009.

VALE, V. S. et. al. When ecological functions are more important than richness: a conservation approach. Journal of Ecology and the Natural Environment, Lagos, v. 2, n. 12, p. 270-280, 2010. 